\title{
A Comparison of Memory Bias or Selective Information Processing between Patients with Social Phobia Disorder and Normal Individuals
}

\author{
Rajabpour Sharbano
}

M.A. in Clinical Psychology, Department of Psychology, Faculty of Humanities, Neyshabur Branch, Islamic Azad University, Neyshabur, Iran

\section{Toozandehjani Hassan*}

Assistant Professor, Ph. D. of Psychology, Department of Psychology, Faculty of Humanities, Neyshabur Branch, Islamic Azad University, Neyshabur, Iran *Corresponding Author Email: H. Toozandehjani@ymail.com

\section{Doi:10.5901/mjss.2016.v7n3s3p97}

\section{Abstract}

In recent years, researches on emotional disorders and phenomenology have been significantly improved. One of these research areas of knowledge is the process of memory bias or information processing in mental disorders. This research is a descriptive and causal-comparative study aimed at investigating selective information processing and role of cognitive attention in this process in patients with social phobia. To this end, two groups of patients with social phobia and normal individuals, each containing 20 individuals, were selected and compared through cluster and random sampling with replacement. The subjects were tested using Stroop test, Recognition test and three questionnaires including Social Anxiety Questionnaire, Spielberger State-Trait Anxiety Inventory and Beck Depression Inventory. For data analysis, one- factor and two-factor variance analysis test with repeated measures and Scheffe post hoc test were applied. The results indicated that patients with social phobia disorder compared to the control group spend more time processing the sings. Further processing of phobia signs was another result of this research. A significant difference was found between the recognition scores of the two groups. This confirms that the processing has been conscious. No significant difference was observed in examining the effect of different anxiety levels. But patients with social phobia disorder who had higher depression levels spent more time processing the signs. Additionally, it was found that variables of age and education have no effect on the process of attentional bias. Considering the obtained results, it can be said that the content of signs has been effective at the time of color determination. Thus, interference effect cannot be attributed to factors such as the length of words or their difficulty or other factors. Further, factors other than anxiety have been effective in slow performance of patients. Existence of schemas commensurate with the threatening signs in memory and cognitive avoidance (attending to stimuli associated with emotional concerns) has led to bias and conscious processing.

Keywords: Memory bias, selective information processing, cognitive attention, social phobia.

\section{Introduction}

Psychologists of information processing approach believe that people process information in different ways. For example, information is processed initially in sensory level, then at conceptual level and finally based on the memories of previous experiences. In each of these levels, information is coded and later while processing, some pieces of information are omitted or distorted.

Lechman and Baterfield believe that information processing approach has provided a fundamentally new way of thinking about human beings for psychologists. In the cognitive approach (over 10 recent years) and in connection with the phenomenology of emotional disorders (specifically, anxiety and depression), significant progress has been made (Cited in Beck \&Weishaar, 1989).

In Broadbent's theory (1954), there were two implications. The first implication was that people do not passively wait for the stimuli to influence them, but they actively search for the stimuli. The second implication stated that seemingly, human information processing is similar to machine control mechanisms (Salkovskis \& jakes, 2002).

According to the cognitive view, anxiety disorders are the result of incorrect, illogical and unrealistic thoughts and beliefs (especially irrational and exaggerated beliefs towards environmental hazards). From psychological perspective, attempts have been made to search for anxiety disorders, including phobia, through the ways in which an individual 
attends to available information and interprets and applies it (Azad, 2002).

Basically, human mental activities can be examined based on three components of outward behavior, emotional activity and cognitive performance. In this regard, psychoanalytic approach focuses on emotional and motivational activities; neurobiological approach lays stress on neurophysiological correlates of psychological components; behavioral approach emphasizes acquired responses to environmental stimuli and cognitive perspective pays attention to active narration of cognitive activities and information processing in activities of affective, emotional, biological and outward behavior (Powell \& Enright; cited in Toozandehjani \& Kamalpour, 1997).

Examining the manner of considering and interpreting external and internal stimuli, method of conscious or subconscious processing of threat stimuli and attentional bias or selective information processing relating to these threats are considered as the subject of this research (Shostack \& Peterson, 1990).

It is believed that people with social phobia disorder tend to do selective processing of threat-related information. In ambiguous issues with two implications, subjects with social phobia are more inclined to choose the concept of threat (Butler \& Mathews, 1993).

Cognitive model focuses on the assumption that people with social phobia compared to patients with anti-social phobia interpret social situations as more threatening. Clark \& Stopa (1993) compared three groups of individuals with social phobia, patients with other anxiety disorders and non-patient subjects. The results showed that the likelihood of adopting negative interpretations by patients with social phobia is significantly greater than other two groups. Patients with social phobia were more inclined than other anxiety disorder patients or non-patient subjects to have catastrophic interpretations about social events (Cited in Kietzman et al., 1990).

Mogg, Mathews and Weinman (1989) stated that individuals with social phobia (compared to other groups) report more negative evaluations in their mind. The assumption of cognitive model has been distorted (Beck, 1976; cited in Beidel, 2000).

Studies by Arntz et al. (1995) and Mansel and Clark (1993) indicate that part of the assessments of patients with social phobia about the dangerousness rate of social situations is based on their own perception of emotional response (Cited in Heimberg \& Barlow, 2001).

Anxious patients usually report thoughts and ideas in relation to issues of personal risk. In different situations, they react as if something dangerous threatens them while the risk is low or there is no danger at all (Beck et al., 1988; Hiebert et al., 1990).

\section{Materials and methods}

This research is a descriptive and causal-comparative study which has been conducted with the aim of investigating selective information processing and role of cognitive attention in this process in students with social phobia and normal individuals. To this end, five schools were selected from among all girl secondary schools in Neyshabouer. Then, Social Phobia Inventory was completed in two classes from each school. The sample consisted of 20 students who obtained the highest score in this questionnaire. Further, 20 normal students who were selected from the same schools through random cluster sampling were part of the sample. The time taken to determine the color of signs was considered as information processing index and recalled signs in recognition test were regarded as the index for conscious processing.

\subsection{Research tools}

The tools used in this study include diagnostic interview, Stroop test, recognition test, stopwatch, social phobia test, Beck Depression Inventory and Spielberger State-Trait Anxiety Inventory.

Diagnostic interview: This interview was carried out based on the interview criteria in Diagnostic and Statistical Manual of Mental Disorders (DSM- IV)and was implemented by psychiatrists and clinical psychologists.

Emotional Stroop test: This test was used in 1935 by Stroop. The signs used in the test included signs of physical threat, signs of social threat, threat signs specific to social phobia and the signs that were emotionally positive. Each of them was randomly presented to the participants with one of the colors of red, blue, green and black in writing. Regardless of the semantic content of the sign, they should register the color of each sign as soon as possible by writing its first letter in front of the sign. The test validity was reported about 0.93 by Jom'epour. Cronbach's alpha coefficient for Stroop test was 0.92 . Also, the reliability of test has been reported to be appropriate.

Recognition test: To provide recognition test, other sixteen signs, i.e. sixteen signs of physical threat, sixteen signs of social threat, sixteen threat signs related to social phobia and sixteen positive signs were selected for each group. None of these signs was applied in the Stroop test (main test), but in terms of content, they were similar to the signs used 
in the main test. The recent four groups of signs in total were added to a total of the four groups of signs used in the main test (128 signs) and the signs were distributed randomly over a separate paper. Test validity in patients with anxiety disorder was published by Jom'epour and posttraumatic stress disorder (PTSD) was reported about 0.89. Additionally, retest reliability was 0.78 which is at an appropriate level.

Stopwatch: A stopwatch with an accuracy of two-tenths of a second to record the time spent.

Beck Depression Inventory: It can be said with absolute certainty that Beck Depression Inventory is the most common means of depression self-evaluation. This scale was developed in 1961 by Aaron Beck and was revised in 1987 in collaboration with Robert Steer. This questionnaire contains 21 articles and examines different aspects of depression. Various studies have reported good validity and reliability for this test (e.g., Beck et al., 1975). The correlation coefficient between pretest scores of Beck Depression Inventory and Hamilton Depression Rating Scale has been reported around 0.66 (Fata, 1991). The overall reliability of questions has been reported about 0.31 to 0.68 by Beck (1972). Also, the overall reliability of questions using Spearman-Brown correlation method was obtained around 0.93 .

Spielberger State-Trait Anxiety Inventory: This questionnaire was developed by Spielberger (1970). It is a selfevaluation (self-report) questionnaire to separately assess state and trait anxiety. The reliability of state anxiety scale was 0.91 and reliability of trait anxiety scale was obtained 0.90 . The scale reliability for the whole test was 0.94 (Mahram, 1993).

Social Phobia Inventory (SPAI): This questionnaire is a self-report scale and includes the questions that assess cognitive and physical aspects and behaviors related to social phobia disorder. Turner and Beidel (2007) reported the validity and reliability of this test to be at an appropriate level (respectively 0.89 and 0.92 ).

\subsection{Research method}

Initially, the first leaf of the test including experiment instructions, two lines of example and five lines of exercise was given to the participants and then, they were asked to read the instructions carefully. The test instruction said that "Several colored words have been written on this page and next pages. You should write the first letter of the color of each word on its right side". The subjects were asked to consider the given example and do the relevant exercise to become fully acquainted with the execution of experiment. Moreover, it was reminded that their time is limited and they must perform this task as soon as possible and with no mistake. After this stage, the subtests were given to the participants, one after the other. The examiner separately recorded the time spent to respond to each of the subtests by a stopwatch. Remarkably, the test was performed individually and the subtests were randomly provided. After performing the main test, recognition test was immediately given to the subjects and they were asked to select from the given list the words that were written with different colors on previous leaves and draw a circle around them.

\subsection{Methods of data analysis}

In this study, descriptive statistics methods were used to determine the demographic characteristics of subjects. But in order to analyze the results, inferential statistics methods such as one-factor and two-factor variance analysis with repeated measures and Scheffe post hoc test were applied.

\section{Research Findings}

Table 1: Summary of the results of two-factor variance analysis with repeated measures on time scores

\begin{tabular}{|c|c|c|c|c|}
\hline Source of changes & Sum squares (ss) & Degrees of freedom (df) & Mean squares (ms) & $\mathrm{F}$ \\
\hline Between individuals & 512.120 & 80 & & \\
\hline$A$ & 42.652 & 5 & 7.352 & 0.854 \\
\hline S/A & 420.224 & 75 & 6.302 & \\
\hline Within individuals & 144.754 & 20 & & \\
\hline $\mathrm{B}$ & 4.452 & 1 & 3.380 & 0.382 \\
\hline S/B & 146.292 & 19 & 7.388 & \\
\hline$A B$ & 82.710 & 5 & 18.328 & 5.750 \\
\hline $\mathrm{B} / \mathrm{A}$ & 398.178 & 75 & 7.502 & \\
\hline Total & 482.894 & 100 & & \\
\hline
\end{tabular}


As the data in Table 1 shows, there is no significant difference in terms of lists factor (A) and groups factor (B) since the calculated $\mathrm{F}$ is smaller than $\mathrm{F}$ in the table $(\mathrm{F}=4.42)$. But there is a significant difference in terms of the interaction between $\mathrm{A}$ and $\mathrm{B}$. According to the obtained results, Scheffe test was used for comparison of means. In this comparison, the calculated $t(6.75)$ is greater than the value of $t$ in the table (4.54).According to the data collected, it is concluded that the researcher's claim about non-homogeneity of groups in terms of attention rate is accepted. Therefore, the research hypothesis that "the group with social phobia has attentional bias or selective information processing" is confirmed.

To test the second and third research hypotheses stating that "semantic processing of the considered signs leads to further recalling them in the recognition test" and "recalling the signs on which more time is spent to be processed is done consciously", two-factor variance analysis test with repeated measures was employed.

Table 2: Summary of the results of two-factor variance analysis with repeated measures on recognition scores

\begin{tabular}{lcccc}
\hline Source of changes & Sum squares (ss) & Degrees of freedom (df) & Mean squares (ms) & F \\
\hline Between individuals & 509.25 & 80 & & \\
\hline A & 195.45 & 5 & 52.732 & 14.91 \\
\hline S/A & 298.90 & 75 & 3.408 & \\
\hline Within individuals & 1210.720 & 20 & 480.52 & 14.64 \\
\hline B & 518.35 & 1 & 42.125 & \\
\hline S/B & 692.55 & 19 & 51.623 & 8.95 \\
\hline AB & 203.45 & 5 & 5.617 & \\
\hline B/A & 381.50 & 75 & & \\
\hline Total & 1624.8 & 100 & & \\
\hline
\end{tabular}

As the data in Table 2 shows, there is a significant difference in terms of lists factor (A) and groups factor (B) since the calculated $\mathrm{F}$ is greater than $\mathrm{F}$ in the table with above-mentioned degrees of freedom. Also, there is a significant difference in terms of the interaction between A and B. According to the obtained results, Scheffe test was used for comparison of means. In this comparison, the calculated $t$ (7.32) is greater than the value of $t$ in the table (4.54).According to the data collected, it is concluded that the researcher's claim about non-homogeneity of groups in terms of attention rate is accepted. Thus, semantic processing of the signs in the Stroop test has led to further recalling them in the recognition test in these patients. On the other hand, in the group of patients with social phobia disorder, more time has been spent on processing the signs. So, we come to the conclusion that this processing has been conducted consciously.

Table 3: Results of one way variance analysis related to depression

\begin{tabular}{lcccc}
\hline Source of changes & Sum squares $(\mathrm{ss})$ & Degrees of freedom $(\mathrm{df})$ & Mean squares $(\mathrm{ms})$ & $\mathrm{F}$ \\
\hline Between groups & 309.182 & 4 & 89.532 & \multirow{2}{*}{9.382} \\
\hline Within groups & 216.636 & 16 & 13.43 & \\
\hline Total & 526.20 & 20 & & \\
\hline
\end{tabular}

Given that the calculated $F(9.382)$ is greater than $(0.05) F$ with the degrees of freedom of 16 and 4 (i.e. 3.01), there is a significant difference between the compared means. Considering the collected data, we conclude that the researcher's claim about non-homogeneity of groups (given their level of depression) in terms of attention rate is confirmed. In other words, attentional bias in subjects with social phobia varies with regard to their level of depression. High levels of depression are accompanied by attentional bias or selective information processing but this is not the same in low levels.

Table 4: Results of one way variance analysis related to state anxiety

\begin{tabular}{lcccc}
\hline Source of changes & Sum squares $(\mathrm{ss})$ & Degrees of freedom $(\mathrm{df})$ & Mean squares $(\mathrm{ms})$ & $\mathrm{F}$ \\
\hline Between groups & 153.642 & 5 & 31.371 & \multirow{2}{*}{0.953} \\
\hline Within groups & 372.123 & 15 & 30.998 & \\
\hline Total & 526.20 & 20 & & \\
\hline
\end{tabular}


Table 5: Results of one way variance analysis related to trait anxiety

\begin{tabular}{|c|c|c|c|c|}
\hline Source of changes & Sum squares (ss) & Degrees of freedom (df) & Mean squares (ms) & $\mathrm{F}$ \\
\hline Between groups & \multirow{2}{*}{62.304} & 4 & 18.357 & \multirow{2}{*}{1.02} \\
\hline Within groups & & 16 & 24.122 & \\
\hline Total & 526.20 & 20 & & \\
\hline
\end{tabular}

Given that the calculated $\mathrm{F}$ is smaller than $(0.05) \mathrm{F}$ with degrees of freedom of 15 and 5 (i.e. 2.90), there is no significant difference between the compared means. Considering the collected data, it is concluded that the researcher's claim about non-homogeneity of groups (given their level of state and trait anxiety) in terms of attention rate is rejected. In other words, attentional bias in subjects with social phobia is not different with regard to their level of state and trait anxiety.

Table 6: Results of one way variance analysis related to the subjects' education

\begin{tabular}{|l|c|c|c|c|}
\hline Source of changes & Sum squares (ss) & Degrees of freedom (df) & Mean squares (ms) & F \\
\hline Between groups & 73.122 & 4 & 24.733 & \multirow{2}{*}{1.152} \\
\hline Within groups & 453.161 & 16 & 23.984 & \\
\hline Total & 526.20 & 20 & & \\
\hline
\end{tabular}

Table 7: Results of one way variance analysis related to the subjects' age

\begin{tabular}{|l|c|c|c|c|}
\hline Source of changes & Sum squares (ss) & Degrees of freedom (df) & Mean squares $(\mathrm{ms})$ & $\mathrm{F}$ \\
\hline Between groups & 54.326 & 3 & 30.172 & \multirow{2}{*}{1.75} \\
\hline Within groups & 482.156 & 17 & 22.103 & \\
\hline Total & 526.20 & 20 & & \\
\hline
\end{tabular}

Given that the calculated $\mathrm{F}$ is smaller than $(0.05) \mathrm{F}$ with degrees of freedom of 16 and 4 (i.e. 3.01), there is no significant difference between the compared means. Considering the collected data, it is concluded that the researcher's claim about non-homogeneity of groups (given their level of education and age) in terms of attentional bias rate is rejected. In other words, attentional bias in patients with social phobia is not different with regard to their level of education and age.

\section{Discussion and Conclusion}

The first finding of the study was that people with social phobia disorder have spent more time processing the signs or have attentional bias and selective information processing. The statistical results showed that there is a significant difference between the groups in the processing of phobia, anxiety and depression signs and also neutral signs, and bias of phobia signs has been more than other mentioned signs.

According to the mechanism of the Stroop paradigm, it can be mentioned that this finding has shown the Stroop interference effect (interference of the sign content in color assignment). Further, this result is consistent with the studies conducted in this area that have confirmed the attentional bias in anxiety disorders (e.g., Mythos, 1984;Jom'epour, 1993; Naziri \& Birashk, 2002; cited in Jalali, 2007). Indeed, to what the interference of physical and social threat signs in color determination of these signs (interference effect) can be attributed?

If we assume that factors such as the length of the written words or their difficulty have had a role in creating this phenomenon (interference effect), we should expect that in both groups (normal subjects and patients with social phobia disorder), a similar pattern of slow performance can be observed which indicates the interference of physical and social threat words at the time of color determination; especially that these two groups were matched in terms of some important variables such as gender, education and age. According to the data, only patients with social phobia disorder showed such a pattern of interference effects. Thus, this interference effect cannot be attributed to factors such as the length of words or their difficulty or possibly other similar factors. If we attribute the interference of physical and social threat words in the performance of color determination only to the anxiety level of individuals, we should expect that these patients also show slow performance in relation to other signs provided in the test (positive symptoms and other signs) while such a phenomenon was not observed among the research findings. Hence, it can be said that if the individuals' anxiety level has had a role in the slowness of their performance in the face of physical and social threat signs, this has been coupled with some other factors (Davidson, 2000). 
Additionally, it can be mentioned that the existence of memory structures (schemas) due to their relevance to physical and social threat signs leads to the attentional bias of the patients with social phobia disorder towards these signs and then, further processing is performed on these signs. Since this process takes time and strength, it has caused the slowness of performance in individuals (color determination of signs). This explanation is consistent with cognitive formulations of recent years about anxiety disorders stating that patients with anxiety have structures (schemas)in their long-term memory that are associated with risk and threat (Beck\& Emery, 1985; Mathews, 1990).Social phobia disorder is also related to bias in information processing about personal threats (Blackburn \& Davidson, 2000). Moreover, it was found that the attentional bias of patients with social phobia disorder is related to actual experiences and past life events (Mathews \& Macleod, 1985).

Regarding selective information processing being conscious or unconscious, researchers have different views. Some say that this process is conscious and some other have suggested the opposite opinion. Since a significant difference was obtained in recognition test scores of this research, it can be said that the level of cognitive attention has been effective in this respect.

Hollon and Kriss (1984) have referred to the methodological problem in discovering the conscious or automatic nature of biases. They argue that for example it is in dichotic listening that the subjects temporarily become aware of the semantic content of the sign, but they quickly forget it during the experiment; that is, processing is done consciously but is quickly forgotten.

Besides, this result is consistent with the studies by Bervin (1994) and Hutton et al. (1990) who have demonstrated the processing of threatening stimuli in patients with posttraumatic stress disorder (PTSD) and panic disorder in the strategic steps of information processing (Cited in Jom'epour, 1993). Further, information provided by Barlow (1998) and Beidel (2000) using dichotic listening model to evaluate the attentional bias in patients with social phobia is consistent with the results of the present study.

The researches carried out by Mathews (1990) to investigate the attentional bias arising from automatic mechanisms in processing threatening information provided the results similar to those of this study. Mathews concluded that subjects who are unable to recall threat words through a recognition test also cannot process the unconscious (automatic)meanings of the threat signs.

Another research with the same results as those of the present study has been conducted by Naziri and Birashk (2002) about patients with obsession disorder and normal individuals. Findings of this study indicated that patients with obsession disorder spend more time reading the color of sin-related signs although the depressed group as compared to the normal group also showed such a delay (Cited in Jalali, 2007).

In this regard, the simplest explanation is that we accept that the processing of threat signs has occurred automatically or pre-attentively. In this case, this view is consistent with those previous results which showed that the processing of threat signs in anxiety disorders occurs automatically or pre-attentively (e.g., Mathews \& Macleod, 1985). The experiment method applied in this study includes the use of Stroop test pattern in which the signs of stimuli (subtest) were collectively given to the subjects while the processing of automated processes occurs very quickly. Judgment about the automaticity of sign processing is very difficult and further study of this phenomenon requires a more precise methodology; for example, the use of tachistoscope that can individually provide the signs for the subject.

Another explanation related to the recent finding is the issue proposed by Hollander (1986) stating that participants may temporarily be aware of the signs' semantic content but they forget it quickly during the experiment (Cited in Mathews, 1990).

And finally, the last explanation is that the phenomenon of "cognitive avoidance" might have prevented the recalling of the signs that were more processed. Foa and Kozak (1986) bring up the phenomenon of cognitive avoidance in this way: Anxious people bias their attention towards those natural stimuli that are related to their emotional concerns. However, this does not necessarily mean higher intakes of these stimuli.

Another research finding was that there is a significant difference between the third level of depression with the first and second levels. In other words, those classified in the third level (moderate to severe depression) compared to the individuals classified in the first and second levels (mild depression) spend more time processing the signs.

Beck believes that these patients have a variety of negative cognitive schemas. These depressive negative schemas remain hidden unless the person is faced with the stressors related to the schema. So, they are activated with the occurrence of the stressor. As previously mentioned, it seems that depressed people participate with difficulty in confrontations and processing of information resulting from experience (Cited in Toozandehjani \& Kamalpour, 1995).

The assumption of cognitive model is that the negative evaluations of patients with social phobia from their performance have been at least somewhat distorted. Compared with the assessment of independent evaluators, people with social phobia estimate their performance as being lower while patients with other anxiety disorders and non-patient 
subjects make a relatively accurate assessment of their performance. Stopa and Clark (1993) found that people with social phobia report more negative thoughts (e.g., l'm boring) during the experiment compared to the control group (Cited in Kietzman et al., 1990).

Another research finding refers to the fact that attentional bias in patients with social phobia varies according to their level of anxiety. In a review of the studies conducted, Trandel and McNally (1997) concluded that most studies have shown attentional bias in people with anxiety, but in depressed patients, there is little evidence for this bias. In contrast, there is strong evidence that depressed people show memory bias, but such findings about people with anxiety are negative.

Based on the research findings, "attentional bias in patients with social phobia disorder varies according to their age and education level". In the study of age factor, individuals with social phobia disorder were classified into three age groups. The results indicated that there is no significant difference between various age groups in terms of attentional bias. In other words, age factor has been ineffective in this process. In evaluating the effect of education level, the same method was used and participants were classified into four education groups. The results of this variable like age variable indicated non-influence of education on information processing.

In this study, attempts have been made to examine the variables that may be more effective in the process of attentional bias. Thus, it is recommended that other demographic variables and other anxiety disorders be considered in subsequent research.

\section{Reference}

Azad, H. (2002). Psychopathology. Tehran: Samt.

Barlow, D. H. (1988). Anxiety and its disorder the nature and treatment of anxiety and panic. New York: The Guildford press.

Beck, A. T. \& Emery, G. (1995). Anxiety disorder and phobias a cognitive perspective. Basic books, New York.

Beck, A. T. \& Weishaar, M. E. (1989). Cognitive therapy. In corsini, R.J \& Wedding, D(Eds.) psychotherapies (fourth edition). (pp.258319). U.S.A: Peacock publishers.

Beck, C. K., Rawlins, R. P., Williams, S. R. (1988). Mental health psychiatric nursing. A holistic life-cycle approach, (second edition). The C.V. Mosby company.

Beidel, D. C. (2000, March). Social anxiety disorder in children and adolescents symposium at the $20^{\text {th }}$ national conference for the anxiety disorder associating of American Washington D.C.

Blackburn, M. \& Davidson, K. (2000). Cognitive therapy for depression and anxiety. London: Black well scientific publications.

Butler, G. \& Mathews, A. (1993). Cognitive processes in anxiety. Adv. Behave. Res.ther, 5, 51-62.

Davidson, J. R.T. (2000). Social Anxiety Disorder Under Scouting. Depression and Anxiety, 11, 93-98.

Foa, E. B., Kozak, M. J. Steketee, G. S. \&McCarthy, P. R. (1998). Imipramine and behavior therapy in the treatment of depressive and obsessive- compulsive symptoms. Immediate and long term effect. British Journal of Clinical Psychology, vol. 31, pp, 249- 292.

Heimberg, R. G., Barlow, D. H. (2001). New developments In Cognitive-Behavioral therapy For Social Phobia. Journal of Clinical Psychiatry 52, 21-30.

Heimberg, R. G. Barlow, D. H. (1991). New development in cognitive-behavioral therapy for social phobia. Journal of clinical psychiatry, $52,21-30$.

Hollon, S. D. \& Kriss, M. (1984). Cognitive factors in clinical research and practice. Clinical psychology Review. 4, 35-76.

Jalali M. (1997). Investigating the effect of model-taking teaching methods and model-taking practice and relaxation on treatment of nonassertiveness behaviors and training assertive behaviors. PhD thesis. Tehran: TarbiatModares University.

Kietzman, M. L. Spring, B. \& Zubin, J. (chapter 4). In Kaplan. H.L, Freedman, A.M \& Sadock, B. j. (1990). Comprehensive textbook of psychiatry. Baltimore. Maryland, Waverly press Inc.

Mathaws, A. (1990). Why worry? The cognitive function of anxiety. Behavior research therapy. Vol. 6, pp. 455-468.

Mathews, A. (1990). Why worry? The cognitive function of anxiety. Behave. Res. Ther, 6,455-468.

Mathews, A. M. \& Macleod, C. (1985). Selective processing of threat uses in anxiety states. Behavior Research and therapy, 23,563-9.

Powell, T. \& Enright, S. (1997). Control of anxiety and stress. Translated by H. Toozandehjani; and Kamalpour, N. (1997).Mashhad: Marandiz Publications and Islamic Azad University of Neyshabur.

Salkovskis, p. \& jakes, I. (2002). Cognitive behavioral factors and the persistence of intrusive thoughts in obsessional problems. Behavioral research and therapy, vol. 27(6), pp, 677-684.

Shostak, B. B. \& Peterson, R. A. (1990). Effects of anxiety sensitivity on emotional responses to a stress task. Behave. Res. The. 6.513521.

Toozandehjani, H. (1995). Cognitive therapy of depression and anxiety. Mashhad: Astan Quds Razavi Publications.

Trandel, D. V. \& McNally. R. J. (1997). Perception of threat cues in post-traumatic stress disorder semantic processing without awareness? Behave. Res. The, 6,469-476. 